\title{
A Comparison of Team-Based Learning Formats: Can We Minimize Stress While Maximizing Results?
}

\author{
Cynthia J. Miller ${ }^{1, *}$, Jeff C. Falcone ${ }^{1}$ \& Michael J. Metz ${ }^{2}$ \\ ${ }^{1}$ Department of Physiology and Biophysics, School of Medicine, University of Louisville, Louisville KY, USA \\ ${ }^{2}$ Department of General Dentistry and Oral Medicine, School of Dentistry, University of Louisville, Louisville KY, \\ USA \\ *Correspondence: Department of Physiology \& Biophysics, School of Medicine, University of Louisville, $500 \mathrm{~S}$. \\ Preston St., Louisville, KY 40202, USA. Tel: 1-502-852-7562. E-mail: cynthia.miller@louisville.edu
}

Received: April 20, $2015 \quad$ Accepted: June 18, $2015 \quad$ Online Published: June 22, 2015

doi:10.5430/wje.v5n4p1 URL: http://dx.doi.org/10.5430/wje.v5n4p1

\begin{abstract}
Team-Based Learning (TBL) is a collaborative teaching method in which students utilize course content to solve challenging problems. A modified version of TBL is used at the University of Louisville School of Medicine. Students complete questions on the Individual Readiness Assurance Test (iRAT) then gather in pre-assigned groups to retake the quiz, given time to utilize their learning resources and discuss each of the questions (Team Readiness Assurance Test-tRAT). Following this discussion, students take an Individual Summative Assessment Test (iSAT) with new questions at a similar cognitive level and content focus. While educational gains of TBL have been shown, student evaluations negatively assessed the teaching method with complaints regarding question difficulty and stress levels. Thus, during implementation of TBL in the School of Dentistry, three main changes were made: (1) The contribution of TBL to the overall grade was reduced (2) TBL questions were cognitively aligned with unit exam questions, and (3) Scratch-off, lottery response cards were used to create a fun, game-like environment. This revised TBL format, compared to the original format, resulted in similar student performance during iRAT and tRAT sessions. However, the revised, low-stress format had significantly higher scores on the iSAT ( $\mathrm{n}=119-161, \mathrm{p}<.05)$. Furthermore, students participating in the revised TBL format reported higher effectiveness of the learning format, higher levels of perceived fairness, and lower stress levels. These results suggest that the qualitative experience of students may be an important consideration that should be carefully evaluated during implementation of a new teaching technique.
\end{abstract}

Keywords: Team-Based Learning, Collaborative Learning, Active Learning, Stress

\section{Introduction}

Team-Based Learning (TBL) was first developed by Dr. Larry Michaelsen in the 1980's for use in business classes (Michaelsen, 1983). Since that time, TBL has been implemented in medical, dental, and other professional schools across the nation (Parmelee, 2010). TBL consists of three basic components: (1) preparation for sessions through readings or other assignments (2) assessment of student preparation through an Individual Readiness Assurance Test (iRAT) and Team Readiness Assurance Test (tRAT) and (3) application of course concepts through activities (Parmelee, Michaelsen, Cook, \& Hudes, 2012). The goal of Team-Based Learning is to allow students to become active participants in their own education by applying their knowledge to solve questions. As opposed to the traditional didactic lecture, in which students are merely exposed to course content, TBL allows students to become accountable for their work, receive timely feedback on their performance, and develop the critical thinking skills necessary to apply their content knowledge (Michaelsen, Knight, \& Fink, 2002).

Team-based learning has been shown to improve professional student performance on examinations, particularly for at-risk students in the bottom quartile of the course (Koles, Stolfi, Borges, Neson, \& Parmelee, 2010). In medical schools, research suggests that TBL improves communication skills and National Board of Medical Examiners shelf examination scores (Hunt, Haidet, Coverdale, \& Richards, 2003; Levine et al., 2004). Furthermore, medical students have been found to have favorable perceptions of the TBL strategy and their interactions with teammates (Vasan, 
DeFouw, \& Compton, 2009). However, while the original format of TBL has been shown to have a positive impact on student performance, this method has often been revised to accommodate differing needs in class sizes, time allocation, curricula, administration, etc. As the method became more popular over the past 30 years, many institutions diverged from the standard TBL methodology (Parmelee, 2010).

At the University Louisville School of Medicine, a revised TBL method has been employed since 2006. In this strategy, the third component of the traditional TBL, during which students typically apply the course concepts through activities, has been replaced with a third assessment. This Individual Summative Assessment Test (iSAT) requires students to utilize the knowledge gained during the team session on new questions at a similar cognitive level. This alteration was primarily made due to the time restrictions imposed by a busy didactic schedule and large class sizes. While positive educational gains of this revised TBL have been documented, and will be presented in the current manuscript, student evaluations often negatively assessed the teaching method with complaints regarding question difficulty and stress levels. This feedback posed a significant concern for faculty interested in extending the teaching method to the School of Dentistry.

It has been reported that dental students experience higher levels of stress than medical students, which can negatively impact academic performance (Birks, McKendree, \& Watt, 2009). Furthermore, high levels of stress among dental students have been associated with mental and physical illness, burnout, and social isolation (Silverstein \& Kritz-Silverstein, 2010; Dahan \& Bedos, 2010). Surprisingly, few studies since the 1980's have examined methods by which to reduce dental student stress (Elani et al., 2014). It is quite clear that the landscape of dental education has changed significantly during that time, with the addition of not only new content areas but also the implementation of new teaching techniques such as active, problem-based, and team-based learning (Par \& Howell, 2015; Bassir, Sadr-Eshkevari, Amirikhorheh, \& Karimbux, 2013; Takeuchi et al., 2015). While the effects of these teaching methods on academic success have been thoroughly evaluated, educators often neglect to assess the impact of the techniques on student stress levels. This is particularly important given the extremely busy didactic and clinical schedules imposed on dental students. Studies suggest that academic workload, study pressures, examinations, and changes in curriculum design can all contribute to dental student stress (Alzahem, van der Molen, Alaujan, Schmidt, \& Zamakhshary, 2011).

Thus, when implementing TBL into the School of Dentistry, it was necessary to make some alterations to the existing model from the School of Medicine, and to thoroughly assess and compare the effectiveness of the two strategies. In order to reduce the stress and frustration levels of students when implementing TBLs in the School of Dentistry, three primary changes were made. First, the contribution of TBL to the overall grade was reduced from $29 \%$ to $2 \%$ to transform the activities from high-stakes to low-stakes. Second, TBL questions were cognitively aligned with unit exam questions. Historically, the medical school TBL questions were developed at an extremely high cognitive level, pushing students to assess their highest level of comprehension. This reflects the overall goal of the Medical Physiology course to prepare students for intricate cases involving human pathologies. On the other hand, the Dental Physiology course focuses on more integrative physiological concepts that are applicable to the practice of dentistry. Thus, it was more appropriate to align the TBL questions in Dental Physiology with the summative unit exams. Lastly, scratch-off, lottery response cards were used to create a fun, game-like environment, as opposed to the written feedback given by faculty proctors in the medical school. This allowed for instantaneous and less stressful feedback in the new dental TBL. It was hypothesized that the revised, low-stress TBL format would result in similar educational gains but an improvement in the qualitative experience of students.

\section{Methods}

\subsection{Participants and Course Design}

This study was completed at the University of Louisville Schools of Medicine and Dentistry in Louisville, Kentucky, United States. Medical Physiology is a general science course for $1^{\text {st }}$ year M.D. students with an enrollment of 160 students, while Dental Physiology is a general science course for $1^{\text {st }}$ year D.M.D. students, with an enrollment of 120 students. The courses are team-taught by faculty members in the Department of Physiology \& Biophysics and follow a systems-based approach. Medical Physiology consists of approximately 10 hours of lecture per week, with additional sessions comprised of Problem-Based Learning (PBL sessions), Patient Simulations with medical mannequins, and Team-Based Learning. Dental Physiology consists of 6 face-to-face contact hours per week, with the majority of the class sessions consisting of engaging lectures as previously described (Miller, McNear, \& Metz, 2013). In engaging lectures, also referred to as broken or interactive lectures, students are given short periods of lecture, followed by "breaks" that can consist of minute papers, problem sets, brainstorming sessions, or open 
discussion. Outside of class, D.M.D students also utilize online learning, comprised of a number of Camtasia videos (http://www.techsmith.com/camtasia.html) and Softchalk exercises (https://www.softchalkcloud.com) custom-designed by the P.I of this study, Dr. Cynthia J. Miller (Miller, Aiken, \& Metz, 2015).

\subsection{General Design of TBL Sessions}

Figure 1 illustrates the general setup of the Team-Based Learning sessions for both Medical and Dental Physiology courses. This method is a modification of the traditional TBL format developed by Michaelsen and Sweet (2008). All students were asked to prepare for the TBL using posted study guides, practice problem sets, professor-designed class notes, and online recordings of the previous class lectures. For part one, the Individual Readiness Assurance Test (iRAT), students report to assigned seating locations and complete ten multiple-choice questions on scantron ${ }^{\circledR}$ response forms. Following this session the response sheets are collected by faculty proctors, but the students retain the questions along with any written notations they have made. For part two, the Team Readiness Assurance Test (tRAT), the students discuss these same questions with their assigned team members. Additionally, students are allowed to consult their notes or textbooks for further guidance on the content. Teams are encouraged during the 45 minute tRAT session to discuss alternative methods in which the content could be assessed, thus brainstorming potential questions for part three. During the final Individual Summative Assessment Test (iSAT), students are asked to complete ten new multiple-choice questions that re-evaluate the same content areas. These questions are peer-reviewed by faculty to ensure that Part one and three questions are at a similar cognitive level. Students have 30 minutes to complete the iSAT questions on scantron ${ }^{\circledR}$ response forms. At the conclusion of the session, students retain the questions and are given the opportunity to view the correct answers and discuss remaining areas of confusion with the professors.

\section{Team-Based Learning (TBL) Format}
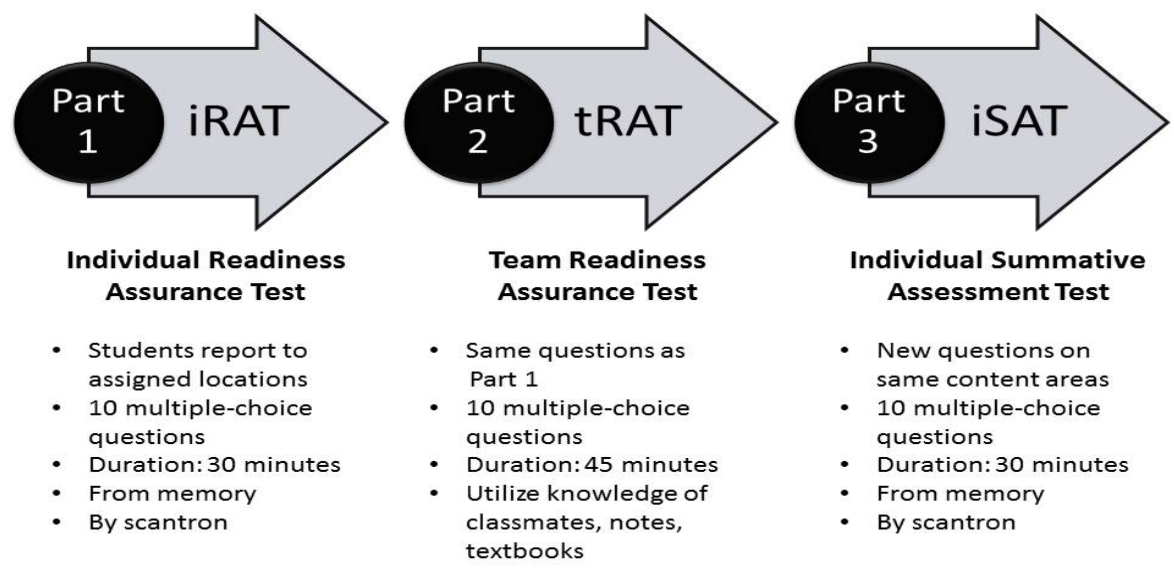

Figure 1. General Schematic for Team-Based Learning

\subsection{Comparison of TBL Design for Medical and Dental Courses}

While the same general setup was used for both Medical and Dental Physiology TBL sessions, there were significant differences in the design shown in Table 1. The first three rows indicate differences between the two groups that were largely outside of the control of this study, while the last three rows indicate changes purposefully made by the investigators. The design of the School of Medicine facility for TBL consisted of six unit labs with capacity for approximately 30 students for the iRAT and iSAT components. Attached to each of the unit labs were three conference rooms that allowed between eight-nine students to discuss the tRAT questions privately. This setup required three faculty proctors, with each proctor being responsible for two unit labs and the six attached conference rooms. The class size during the current study was 161 students, with one student repeating the course following unsuccessful completion during the previous year.

The School of Dentistry lacks the unit labs present in the School of Medicine facilities, so the TBL sessions were held in a large auditorium with capacity for 435 occupants. Each team was comprised of four students, and teams were assigned seat locations in the large room that prohibited communication between different groups. For this 
study, 119 students were enrolled in the course, with one student withdrawing from the program prior to completion of the study.

Table 1. Comparison of TBL formats for Medical and Dental Physiology

\begin{tabular}{|c|c|c|}
\hline & Medical Physiology & Dental Physiology \\
\hline History & $\begin{array}{l}\text { TBL units first implemented in } 2006 \text {, } \\
6 \mathrm{TBLs} / \text { course }\end{array}$ & $\begin{array}{l}\text { Pilot TBL units implemented in } \\
2013,2 \text { TBLs/course }\end{array}$ \\
\hline Environment & $\begin{array}{l}\text { Students distributed into } 6 \text { unit labs } \\
\text { for parts } 1 \text { and } 3,18 \text { adjacent } \\
\text { conference rooms for part } 2\end{array}$ & $\begin{array}{l}\text { All parts completed in large } \\
\text { auditorium (capacity of 435) }\end{array}$ \\
\hline Group Size & $\begin{array}{l}\text { Class size of } 161 \text { with } 9 \text { students per } \\
\text { group }\end{array}$ & $\begin{array}{l}\text { Class size of } 119 \text { with } 4 \text { students per } \\
\text { group }\end{array}$ \\
\hline Overall $\%$ of grade & $\begin{array}{l}\text { Each part weighted eaually, } 29 \% \text { of } \\
\text { overall grade }\end{array}$ & $\begin{array}{l}\text { Each part weighted eaually, } 2 \% \text { of } \\
\text { overall grade }\end{array}$ \\
\hline Difficulty level of questions & Higher cognitive lever than exams & Alighted with exams \\
\hline Format of part2(tRAT) & Hand graded by 3 faculty proctors & $\begin{array}{l}\text { IF-AT forms with w proctors } \\
\text { available }\end{array}$ \\
\hline
\end{tabular}

During implementation of TBL in the School of Dentistry, three main changes were planned, as indicated in the last three rows of Table 1. First, the contribution of the TBL to the overall grade in the course was reduced. In Medical Physiology, six TBLs were administered during the course that comprised $29 \%$ of the overall grade. To pilot the current study, two TBLs were implemented into the Dental Physiology course that comprised 2\% of the students' grades. Each portion of the TBL (iRAT, tRAT, and iSAT) was weighted equally.

While the questions on the dental TBL assessments were still at high levels on Bloom's Taxonomy, they were developed to be aligned with the cognitive level of unit exams in the course. Conversely, the medical school TBL questions are at a higher cognitive level than the unit exams in the course. For example:

Sample TBL question from Medical Physiology:

Which of the following is FALSE related to proximal tubular function?

A. If GFR is $120 \mathrm{ml} / \mathrm{min}$, urine flow rate is $1 \mathrm{ml} / \mathrm{min}$, and plasma $\mathrm{X}$ is $2 \mathrm{mg} / \mathrm{ml}$ and urine $\mathrm{X}$ is $60 \mathrm{mg} / \mathrm{ml}$; then net reabsorption is filtered amount minus excreted amount for substance $\mathrm{X}$.

B. Sodium reabsorption by the proximal tubule is not Tm limited, it is instead limited by the paracellular sodium concentration gradient that will be developed at some time along the length of the proximal tubule.

C. *If GFR is $120 \mathrm{ml} / \mathrm{min}$, urine flow rate is $1 \mathrm{ml} / \mathrm{min}$, and plasma $\mathrm{X}$ is $2 \mathrm{mg} / \mathrm{ml}$ and urine $\mathrm{X}$ is $60 \mathrm{mg} / \mathrm{ml}$; then net reabsorption of $\mathrm{X}$ is $60 \mathrm{mg} / \mathrm{min}$.

D. Increasing GFR by increasing glomerular capillary pressure will be matched by increased tubular reabsorption because of increased PCOP in the peritubular capillary circulation.

E. A reduced Tm for glucose one day after abdominal surgery very likely indicates a decrease in the number of nephrons being perfused within one or both kidneys.

* denotes correct answer

Sample TBL question from Dental Physiology:

Which of the following would result in the lowest concentration of sodium in the urine?
A. High $\mathrm{ADH}$, high Aldosterone, high ANP
B. High ADH, low Aldosterone, high ANP
C. Low ADH, low Aldosterone, high ANP
D. *Low ADH, high Aldosterone, low ANP
E. Low ADH, low Aldosterone, low ANP 
* denotes correct answer

The third and final, planned change in the two TBL formats was the proctor format for Part 2: the tRAT. In Medical Physiology, teams answered all ten questions on the tRAT, and then submitted their handwritten answers to a faculty proctor for grading. Any incorrect answers were circled in red ink, and the students returned to their groups to submit subsequent responses as necessary. In the pilot TBL sessions in the Dental School, Immediate Feedback Assessment Technique (IF-AT) forms were utilized (Epstein Educational Enterprises, Cincinatti, OH). These scratch-off, lottery-style cards enable teams to receive immediate feedback on the submitted responses. For each question, the correct response (A-E) is indicated by a star beneath an easily removed silver material. If the scratched-off response does not contain this star, it indicates that an incorrect answer was chosen and teams must try again to solve the question. Several different versions of the cards can be ordered, with each version containing a different pre-determined key. Faculty members must scramble their response items to match the pre-determined key. The code for the keys is shown on a perforated strip at the bottom of the card for easy removal prior to student distribution. This method requires minimal intervention of faculty members during the tRAT session, thus reducing the need for multiple faculty proctors.

\subsection{Assessments}

All of the questions were peer-reviewed by faculty in the Department of Physiology \& Biophysics to determine appropriate content level and verify that each question had one best answer from the five responses (A-E). iRAT and iSAT scantron ${ }^{\circledR}$ response forms were read, and each question comprised $10 \%$ of the total grade for that assessment. On the tRAT, points were deducted for each incorrect "guess" submitted by teams with reductions in percentage from $10 \%$ (correct on first attempt), 5\% (correct on second attempt), $2 \%$ (correct on third attempt), 1\% (correct on fourth attempt), and $0 \%$ (correct on fifth attempt).

\subsection{Formation of Teams}

Teams for the tRAT portion of the TBL were designed by the course directors of the medical and dental classes to contain students with a range of academic performance levels. Custom excel files were developed that matched one top-performing student (based on their current average in the course), one lower-performing student, and two mid-level-performing students. The mean team averages in the course were within 5\% from one another. The classes are comprised of approximately $50 \%$ of each gender, so no attempts were made to assign teams based on sex or other characteristics. New TBL teams were assigned for each session, in order to enable students to work with a variety of new classmates throughout the semester.

\subsection{Survey Tool}

Following completion of the final TBL session and the corresponding summative unit exams, students were administered a survey containing 13 Likert-scale questions and two open-response questions. These consisted of both positive and negative stems that were developed by the investigators of the study. The goal of the survey was to determine any differences in student perceptions of the TBL effectiveness, team communication, question difficulty level, and stress level. Multiple questions were developed to assess each of these four themes, and were mixed within the survey instrument. Students were given the opportunity to complete a hard-copy of the survey following the final TBL in the course. The response rate for medical students was 96\% (154/161) and dental students was $89 \%$ (106/119). For the Likert Scale: 1=Strongly Disagree, 2=Disagree, 3=Neither Agree nor Disagree, 4=Agree, $5=$ Strongly Agree. For the open-response questions, students were asked to respond to two prompts: 1 . What are the main strengths of the TBL? 2. What changes would help the TBLs achieve the learning objectives of the course? Open-responses were analyzed using a grounded theory approach to determine themes.

\subsection{Data Analysis and IRB Approval}

Statistical analyses were performed using Origin software version 8.1 (OriginLab, Northampton, MA), as shown in the figure legends, with statistical significance defined as $p<.05$. This study was determined to be IRB exempt by the University of Louisville (Tracking \#: 13.0267, 6/26/2013).

\section{Results}

\subsection{TBL Performance Results}

Student averages from each of the TBL sections are shown in Figure 2. The data from medical students, shown on the left, is comprised of averages from 6 TBLs, while the dental school data on the right consists of student averages from the 2 pilot TBL sessions. All pairwise comparisons were performed using one-way analysis of variance and the 
Tukey post-hoc test. The revised dental TBL format, compared to the original medical format, resulted in similar student performance during iRAT and tRAT sessions. However, the revised, low-stress format had significantly higher scores on the iSAT $(n=119-161, p<.05)$.

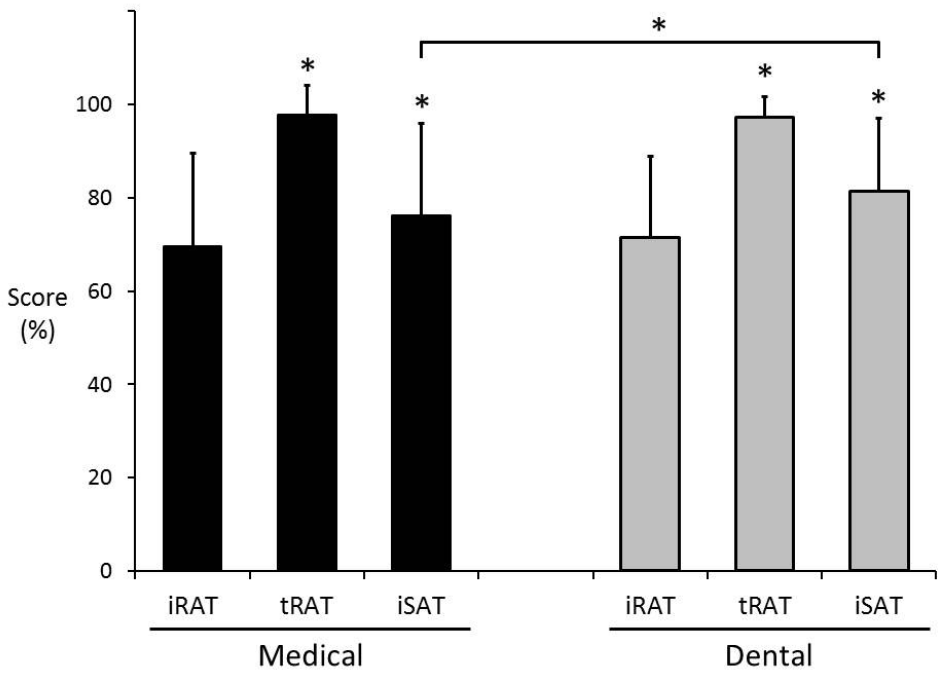

Figure 2. Comparison of TBL Performance for Medical and Dental Students

For medical data: $\mathrm{n}=6$ TBLs, 161 students, 966 individual scores; For dental data: $\mathrm{n}=2$ TBLs, 119 students, 238 individual scores. Data presented as means $\pm \mathrm{SD},{ }^{*} \mathrm{p}<.05$, One-way ANOVA and Tukey post-hoc test.

\subsection{Survey Results}

In order to compare student perceptions of the two TBL formats, Likert-scale surveys were administered. Figure 3 compares the student perceptions of the overall effectiveness of the teaching method. Dental students indicated more positive perceptions of the impact of TBL on their understanding of class content, exam performance, and benefits in learning ( $\mathrm{n}=106-154$, Mann-Whitney U test for non-parametric, ordinal data).

\section{Overall Perceived Effectiveness of TBLs}

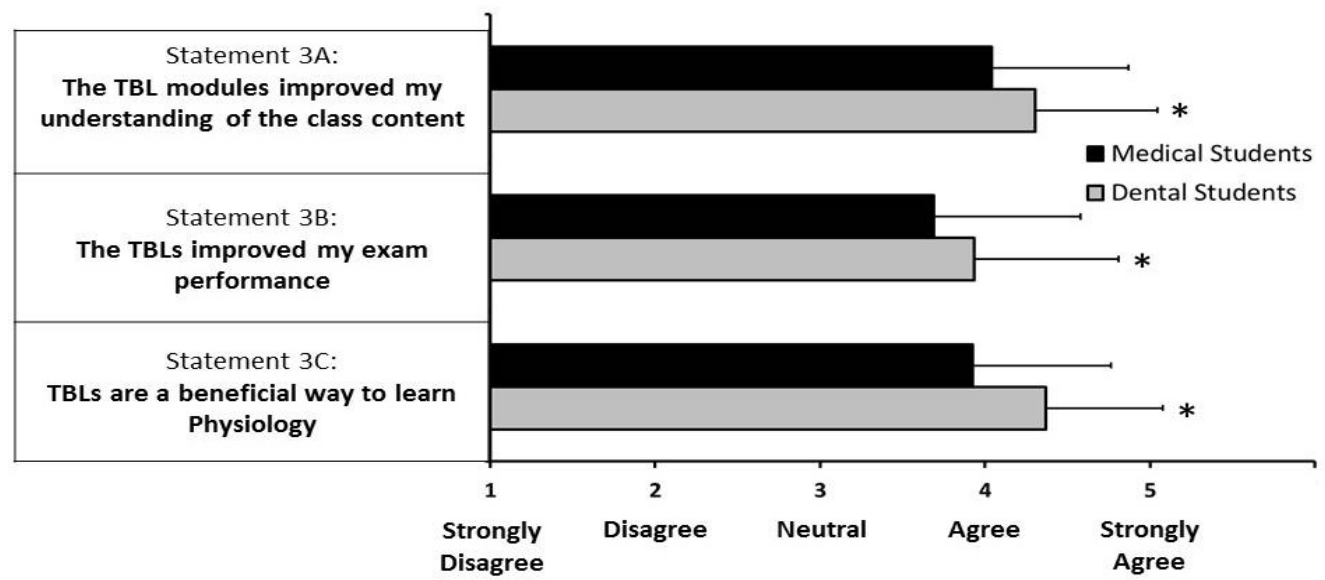

Figure 3. Likert-scale Survey Data on Student Perceptions of TBL Effectiveness

$\mathrm{n}=106-154$, data presented as means $\pm \mathrm{SD}, * \mathrm{p}<.05$, Mann Whitney $\mathrm{U}$ test used for non-parametric, ordinal data

It was also necessary to determine if the revised TBL strategy had an effect on group dynamics during the session. As shown in Figure 4, there were no significant differences between the two groups when asked to evaluate the communication of the team, personal contribution to the team, or peer-assistance during the session. All responses 
positively evaluated the effectiveness of team interactions with mean scores ranging from 3.95-4.24 on the 5-point Likert scale.

\section{Effectiveness of Team Interactions}

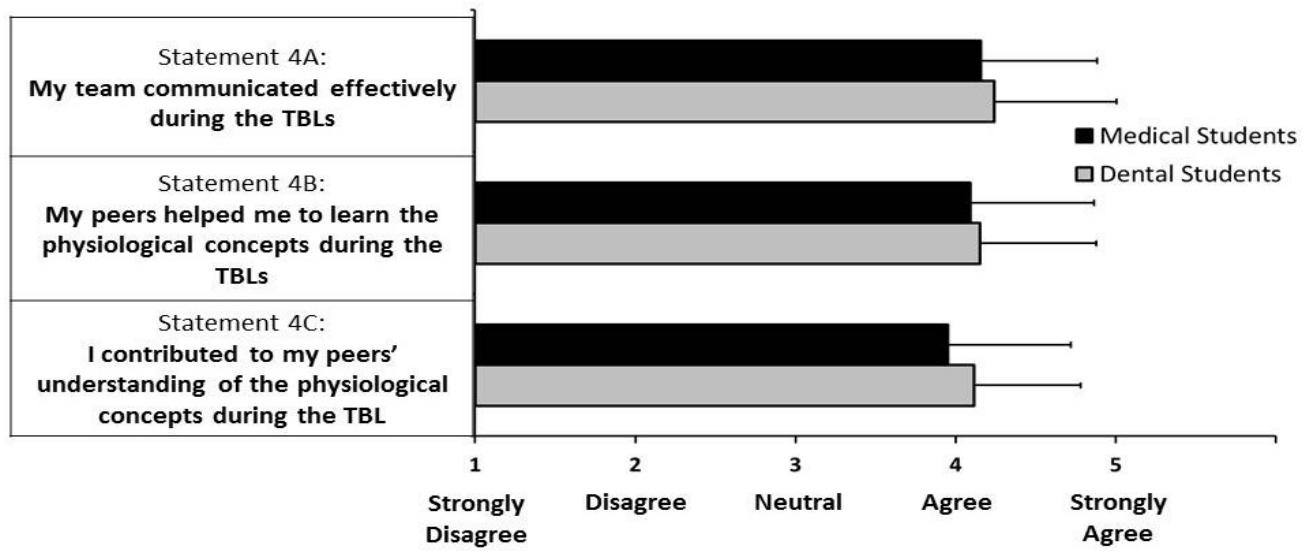

Figure 4. Likert-scale Survey Data on Student Perceptions of Team Effectiveness

$\mathrm{n}=106-154$, data presented as means $\pm \mathrm{SD}, * \mathrm{p}<.05$, Mann Whitney $\mathrm{U}$ test used for non-parametric, ordinal data

A major concern with the pre-established medical school TBL format was the student perception of fairness and question difficulty level. Indeed, Figure 5 indicates that the medical students involved in the higher-stress TBL format, when compared to the dental students, reported that the TBL questions were more difficult than exam questions, the questions were less fair, and that their scores on the TBL did not as accurately reflect their understanding of the material. Furthermore, the differences between the medical and dental students were statistically significant, with mean responses differing by $0.72,1.27$, and 1.08 points respectively on a 5-point Likert scale $\left({ }^{*} p<.00001\right)$. The perceived lack of fairness may also impact student stress levels, as displayed in Figure 6. Dental students perceived the revised TBL method to be less stressful and less frustrating than their medical school counterparts.

\section{Perception of Question Difficulty Level and Fairness}

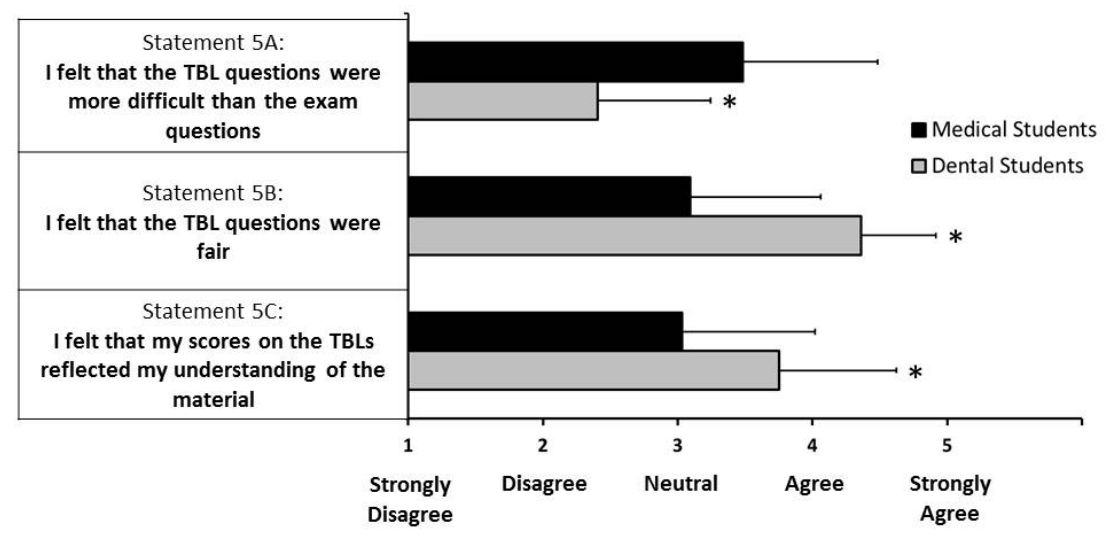

Figure 5. Likert-scale Survey Data on Student Perceptions of Question Difficulty Level and Fairness $\mathrm{n}=106-154$, data presented as means $\pm \mathrm{SD},{ }^{*} \mathrm{p}<.00001$, Mann Whitney $\mathrm{U}$ test used for non-parametric, ordinal data 


\section{Student Stress Levels}

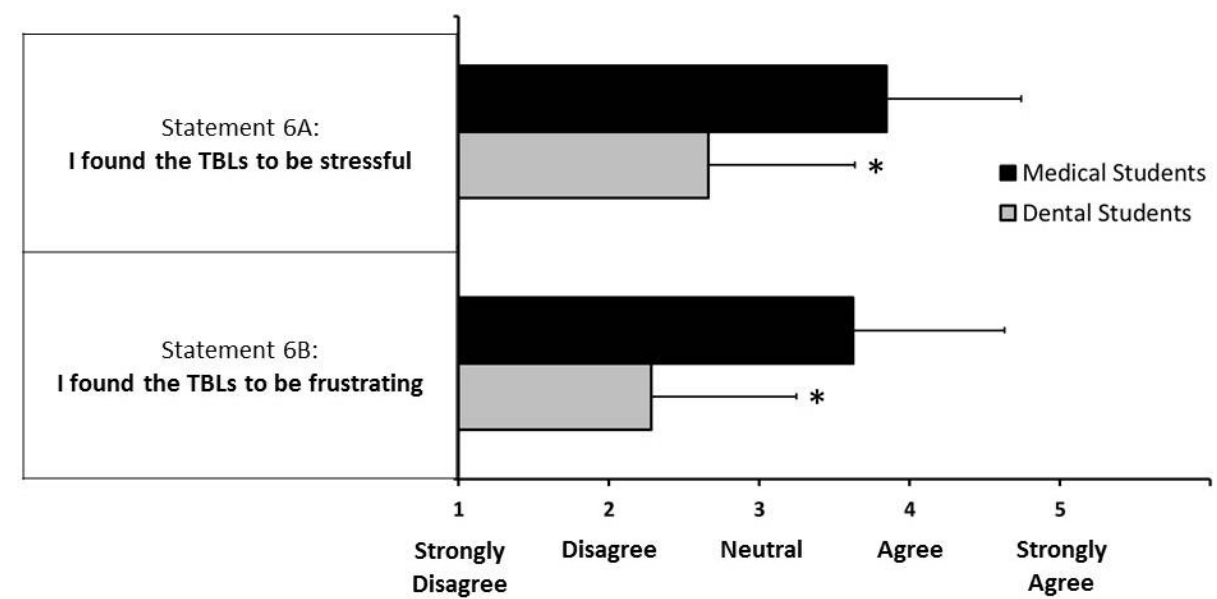

Figure 6. Likert-scale Survey Data on Student Perceptions of Their Stress Levels

$\mathrm{n}=106-154$, data presented as means $\pm \mathrm{SD}, * \mathrm{p}<.00001$, Mann Whitney $\mathrm{U}$ test used for non-parametric, ordinal data

On the open-response questions, the following three strengths of TBL were emphasized by both medical and dental students:

- Learning from classmates and peer interactions (66 medical students, 32 dental students)

- Time management and a reduction in procrastination (59 medical students, 17 dental students)

- Preparation for exams (42 medical students, 77 dental students)

Additionally, many dental students (33) reflected on the ability of TBL to improve their understanding of the content by identifying areas of strength and weakness. A dental student commented, "The TBL benefits everyone. It benefits those that understand the material well, because they will teach it more and therefore understand the material better. To the people who are struggling with the material, they will get different points of view teaching it to them as a team."

When asked what changes would help to achieve the learning objectives of the course, the medical students largely reported a reduction in question difficulty, or an increase in the clarity of questions (38). As one medical student wrote, "We don't go through TBL style questions in class, so they are significantly more difficult than the material presented in class. They seem to be designed to trip you up and confuse you rather than to clarify and re-teach the course material. It seems as if the professors enjoy making excessively difficult questions, then refuse to help understand the concept under the guise of "student learning." They are paid to teach us when we are confused. I learn very little from eight other equally confused students."

The dental students participating in the revised TBL format primarily suggested that more TBL sessions be incorporated into the course, or that more questions be included on each TBL (29).

\subsection{Instructor Observations from the Dental Physiology Course Director}

There was significant faculty apprehension regarding the implementation of TBL in the School of Dentistry, due to previous interactions with medical students. Through informal conversations with medical students, there were many complaints that the faculty were "trying to trick them" with the TBL questions. Some students did, however, recognize the educational benefit of the process despite their frustration levels. Both medical and dental students have extremely busy and often stressful schedules, and there was concern that implementation of the new teaching technique with dental students would only compound these issues.

When introducing TBL to the dental students, students were encouraged to use their team-members' knowledge to help grow in their own comprehension of the material. During the very first iRAT session, a number of students did appear to be stressed, but this seemed to disappear during the tRAT session as students began to work together. Particularly, once they began scratching items off of the IF-AT forms, simultaneous exclamations of joy or 
(good-natured) groans could be heard echoing throughout the large room. The students were without a doubt having fun during the process, and I personally enjoyed eavesdropping on some extremely enriching conversations. The overwhelming response of the students was that they wanted a TBL session prior to each of the four unit exams in the course. Time-allowing, this will be implemented into next year's course, along with a longer (50 question) session to review for the final exam.

\section{Discussion}

Team-Based Learning has been used in the University of Louisville School of Medicine since 2006 and has shown positive educational effects on student performance. However, the students often expressed negative reviews of the TBL process. The literature suggests that other institutions may experience similar difficulties in implementation, but that student attitudes toward TBL may improve with time and refinement of the teaching technique (Davidson, 2011). A study conducted at Baylor College of Medicine and the University of Texas, Houston College of Medicine reported that while TBL resulted in similar educational results relative to traditional didactic lectures, the medical residents more favorably perceived the lectures (Haidet, Morgan, O’Mallery, Moran, \& Richards, 2004). Interestingly, their study also utilized a revised TBL strategy from the original format.

Michaelsen and Richards acknowledged that it may be difficult to extend the traditional TBL format into health sciences education, and these alterations may diminish the effectiveness of the teaching strategy (2005). The integration of multiple courses in professional curricula, high number of lecturers, and attendance issues were all cited as potential areas of difficulty. It has been argued that the classic TBL format is well-tested and that divergence from this method will negatively impact student learning (Parmelee, 2010). In the original concept of TBL, Michaelsen proposed that active learning sessions follow the iRAT and tRAT portions. However due to large class sizes and time constraints, the School of Medicine at UofL replaced the active learning component with summative iSAT questions. Thus, to best compare the effectiveness of the Dental Physiology pilot TBL sessions, it was necessary to follow this established model at the institution.

One major difference between the two TBL formats compared in the present study was the cognitive level of the exam questions. The original, medical school TBL format had questions at a much higher cognitive level than exam questions. In the revised, low-stress dental TBL, students were asked to answer questions at a cognitive level aligned with the unit exams. On surveys, the students confirmed their perceptions of this change, with medical students reporting that the TBL questions were more difficult than exam questions, the questions were less fair, and that their scores on the TBL did not as accurately reflect their understanding of the material. Another major change was that the contribution of the TBL sessions to the overall grade was reduced from $28 \%$ to $2 \%$, in an attempt to reduce student stress levels during the formative TBL assessments. High-stakes assessments have been found to lower the motivation to learn, and to emphasize attainment of scores rather than mastery of course concepts (Harlen \& Crick, 2003). Research suggests that for formative assessments to be most successful, they must be administered under situations that are as stress-free and low-stakes as possible (Rolfe \& McPherson, 1995).

Another stress reduction strategy was the employment of a lottery-style, scratch-off cards during the team portion of the TBL. It has been argued that professional education has been extremely resistant to games and other innovative educational techniques, but that these strategies are beneficial in improving student comprehension, interest in the material, and interaction with classmates (Handfield-Jones \& Nasmith, 1993). The goal of the scratch-off cards was to allow students instantaneous feedback on their group performance, while also reducing stress during the TBL session due to the fun atmosphere. Use of the IF-AT forms has been found to decrease student misconceptions of the material, while also improving long-term retention of the content relative to traditional testing techniques (Epstein et al., 2002).

Surprisingly, despite these changes to the TBL design, there were no significant differences in iRAT and tRAT scores between the medical and dental students. This may attest to the different focuses and expectations of the programs. The medical school curriculum strives to push students to a very high comprehension of physiology, in order for students to fully comprehend all pathologies and treatments of the human body. Conversely, the dental school curriculum is designed to emphasize long-term mastery of more basic physiological processes that relate to dentistry. Thus, due to the very nature and expectations of the courses, students may be rising to similar levels of achievement on TBL questions, despite differences in the cognitive level.

In both TBL formats, there was a statistically significant improvement in tRAT and iSAT scores relative to the preceding iRAT scores. The improvement in tRAT scores would be expected, since partial credit is given for incorrect answers and the students are also working in teams. It is intuitive that team performance and assimilation of 
knowledge would surpass that of the individual. Indeed, previous research has shown that collaborative examinations improve student scores on physiology exams, particularly for at-risk students with poor individual performance levels (Giuliodori, Lujan, \& DiCarlo, 2008). It was shown that students were more likely to change their responses to correct answers in a group setting, and that long-term retention of the information was improved following collaborative examinations (Cortwright, Collins, Rodenbaugh, DiCarlo, 2003; Giuliodori, Lujan, \& DiCarlo, 2009). Furthermore, the "open-book" design of the tRAT session would be predicted to raise performance levels (Agarwal, Karpicke, Kang, Roediger, \& McDermott, 2008). Thus, the inherent design of the tRAT session would be expected to cause a significant increase from the iRAT.

The dental students participating in the low-stress TBL format showed significantly higher performance levels than medical students on the final iSAT section (5.2\% increase). This could indicate that the lower cognitive level of the questions allowed the dental students to better master the concepts in the discussion time provided. This was supported by the fact that a large number of dental students reflected on the ability of TBL to improve their understanding of the content by identifying areas of strength and weakness. Conversely, the lower stress level during dental TBL may have positively impacted the students' ability to gain knowledge during the session. As one medical student participating in the high-stress TBL commented, "People get too stressed and frustrated about the right answer when tied to a grade and it reduces the ability to think clearly and learn the underlying concepts."

Stress may be an inherent component of any professional program, as students are pushed to their mental, physical, and educational limits. Thus, it was of paramount importance that the new TBL sessions did not increase the stress imposed on dental students. Indeed, dental students participating in the revised TBL format reported lower levels of stress and frustration, when compared to the medical students. Previous studies by our group indicated that dental students were often overwhelmed by their responsibilities in and out of the classroom (Miller, McNear, \& Metz, 2013). In fact, one study showed that dental students were more likely than medical students to experience psychological stress, with $20.4 \%$ of the dental students exhibiting pathological results compared to $5.5 \%$ of medical students (Prinz, Hertrich, Hirschfelder, \& De Zwaan, 2012). While some established professors may envision that students must "pay their dues" by suffering through professional programs, research has shown that stress negatively impacts memory retrieval (Kuhlmann, Piel, \& Wolf, 2005). Furthermore, the continual presence of stress may contribute to a reduction in empathy that occurs as students' progress through their educational careers (Neumann et al., 2011).

Lack of empathy may inhibit health care providers from interacting proficiently with both patients and fellow clinicians. Team dynamics are difficult to establish, and it has been shown that students have poor perceptions of group work in educational settings (Troth, Jordan, \& Lawrence, 2012). One of the main components of the TBL format designed by Michaelsen was the development of consistent groups that unified as the course proceeds (2008). In the current study, however, new assigned groups were formed for each of the study sessions.

As previously described by our group, the remaining face-to-face class time in Dental Physiology employs engaging lectures (Miller, McNear, \& Metz, 2013). In this teaching method, students are given short periods of lecture, following by "breaks" in which they work with classmates to complete activities such as completing one-minute papers, hypothesizing patient outcomes, classifying components, etc. The collaborative nature of these activities creates strongly-unified, but self-selected groups in the classroom. Further data collected demonstrated that at-risk students may poorly select partners for these classroom activities, which may lead to not only deficiencies in knowledge, but also ultimate failure of the course (Miller \& Metz, 2014). Thus, during the pilot TBL sessions, it was desired to create new group assignments each time, in order to allow students to interact with additional classmates and build an increased support network in the class. However, it has been suggested that newly formed teams may experience interactions that cause high anxiety and uncertainty (Sweet \& Michaelson, 2007). Thus, it is widely recommended that student teams be consistent for all TBL sessions in a course (Michaelsen, 2008). Despite the new teams assigned for each TBL in the current study, students subjectively reported high levels of team effectiveness on the surveys. There were no significant differences between the perceived team effectiveness of the two formats, despite large differences in group sizes (four students vs. nine students) and classroom environment for the team sessions. Thus, alteration of the classic method of TBL group formation may be beneficial in some cases, depending on the other alternative teaching strategies being employed.

One large confounding variable that could affect the current study is that two different populations of health sciences students were compared. Both medical and dental students are admitted through a rigorous admissions process, and have extremely high entrance exam scores and GPA. In 2013, the year in which the current study was completed, the entering medical school class had a cumulative undergraduate GPA of 3.64, science GPA of 3.56, and biological 
science MCAT score of 10.05 (University of Louisville School of Medicine, 2015). The entering dental school class had a cumulative undergraduate GPA of 3.51, science GPA of 3.39, and biology DAT score of 19 (University of Louisville School of Dentistry, 2015). Thus, the two groups involved in the study appeared to have similar academic backgrounds. However, some studies have shown that while students entering into professions in the health sciences may have similar academic success, there may be different reasons that motivate students to choose their respective fields. For example, one such study found that medical students are motivated to enter their field due to career opportunities, an interest in science, and a desire to work with people, while students were motivated to choose dentistry in response to more personal factors such as working hours, independence, and security (Crossley \& Mubarik, 2002). Consequently, there could be inherent differences between the two populations examined in this study which could skew results. Steps will be taken in future studies to determine if a revision to the medical school TBL, which reduces the stress level for students, would produce similar qualitative improvements while maintaining the educational benefits.

\section{Conclusion}

Most educational studies on the Scholarship of Teaching and Learning (SOTL) focus on improvements in student comprehension of material. This is a lofty goal, and one that is certainly important for student success. However, despite having similar focuses, educational studies from different groups often find conflicting results and reproducibility continues to be an issue in SOTL (Kember, 2003). The current study indicated that the qualitative experience of students is an important consideration that should not be neglected. Implementation of a low-stress TBL in the dental curriculum resulted in similar educational gains but an improved student qualitative experience. Dental students indicated more positive perceptions of the impact of TBL on their understanding of class content, exam performance, and benefits in learning. This indicates that alterations to traditional teaching methods may have drastic effects on student perceptions of the technique, and should be carefully evaluated in all educational studies.

\section{References}

Agarwal, P. K., Karpicke, J. D., Kang, S. H. K., Roediger, H. L., \& McDermott, K. B. (2008). Examining the testing effect with open- and closed-book tests. Applied Cognitive Psychology, 22, 861-876. http://dx.doi.org/10.1002/acp.1391

Alzahem, A. M., van der Molen, H. T., Alaujan, A. H., Schmidt, H. G., \& Zamakhshary, M. H. (2011). Stress among dental students: a systematic review. Eur $J$ Dent Educ, 15, 8-18. http://dx.doi.org/10.1111/j.1600-0579.2010.00640.x

Bassir, S. H., Sadr-Eshkevari, P., Amirikhorheh, S., \& Karimbux, N. Y. (2014). Problem-based learning in dental education: A systematic review of the literature. J Dent Educ, 78(1), 98-109.

Birks, Y., McKendree, J., \& Watt, I. (2009). Emotional Intelligence and perceived stress in health care students: a multi-institutional, multi-professional survey. BMC Med Educ, 9, 61. http://dx.doi.org/10.1186/1472-6920-9-61

Cortwright, R. N., Collins, H. L., Rodenbaugh, D. W., \& DiCarlo, S. E. (2003). Student retention of course content is improved by collaborative-group testing. Adv Physiol Edu, 27(3), 102-108. http://dx.doi.org/10.1152/advan.00041.2002

Crossley, M. L., \& Mubarik, A. (2002). A comparative investigation of dental and medical students' motivation toward career choice. British Dental Journal, 193(8), 471-473. http://dx.doi.org/10.1038/sj.bdj.4801599

Dahan, H., \& Bedos, C. (2010). A typology of dental students according to their experience of stress: a qualitative study. J Dent Educ, 74(2), 95-103.

Davidson, K. L. (2011). A 3-year experience implementing blended TBL: Active instructional methods can shift student attitudes toward learning. Medical Teacher, 33, 750-753. http://dx.doi.org/10.3109/0142159X.2011.558948

Elani, H. W., Allison, P. J., Kumar, R. A., Mancini, L., Lambrou, A., \& Bedos, C. (2014). A systematic review of stress in dental students. $J$ Dent Educ, 78(2), 226-242.

Epstein, M. L., Lazarus, A. D., Calvano, T. B., Matthews, K. A., Hendel, R. A., Epstein, B. B., \& Brosvic, G. M. (2002). Immediate feedback assessment technique promotes learning and corrects inaccurate first responses. The Psychological Record, 52, 187-201.

Giuliodori, M. J., Lujan, H. L., \& DiCarlo, S. E. (2008). Collaborative group testing benefits high- and 
low-performing students. Adv Physiol Edu, 32, 274-278. http://dx.doi.org/10.1152/advan.00101.2007

Giuliodori, M. J., Lujan, H. L., \& DiCarlo, S. E. (2009). Student interaction characteristics during collaborative group testing. Adv Physiol Edu, 33, 24-29. http://dx.doi.org/10.1152/advan.90161.2008

Haidet, P., Morgan, R. O., O’Mallery, K., Moran, B. J., \& Richards, B. F. (2004). A controlled trial of active versus passive learning strategies in a larger group setting. Advances in Health Sciences Education, 9, 15-27. http://dx.doi.org/10.1023/B:AHSE.0000012213.62043.45

Handfield-Jones, R., \& Nasmith, L. (1993). Creativity in medical education: The use of innovative techniques in clinical teaching. Medical Teacher, 15(1), 3-11. http://dx.doi.org/10.3109/01421599309029005

Harlen, W., \& Crick, R. D. (2003). Testing and motivation for learning. Assessment in Education, 10(2), 169-207. http://dx.doi.org/10.1080/0969594032000121270

Hunt, D. P., Haidet, P., Coverdale, J. H., \& Richards, B. F. (2003). The effect of using team learning in an evidence-based medicine course of medical students. Teaching and Learning in Medicine, 15(2), 131-139. http://dx.doi.org/10.1207/S15328015TLM1502_11

Kember, D. (2003). To control or not to control: the questions of whether experimental designs are appropriate for evaluating teaching innovations in higher education. Assessment and Evaluation in Higher Education, 28(1), 89-101. http://dx.doi.org/10.1080/02602930301684

Koles, P. G., Stolfi, A., Borges, N. J., Neson, S., \& Parmelee, D. X. (2010). The impact of team-based learning on medical students' academic performance. Academic Medicine, 85(11), 1739-1745. http://dx.doi.org/10.1097/ACM.0b013e3181f52bed

Kuhlmann, S., Piel, M., \& Wolf, O. T. (2005). Impaired memory retrieval after psychosocial stress in healthy young men. The Journal of Neurosciences, 25(11), 2977-2982. http://dx.doi.org/10.1523/JNEUROSCI.5139-04.2005

Levine, R. E., O’Boyle, M., Haidet, P., Lynn, D., Stone, M. M., Wolf, D. V., \& Paniagua, F. A. (2004). Transforming a clinical clerkship through team-learning. Teaching and Learning in Medicine, 16(3), 270-275. http://dx.doi.org/10.1207/s15328015tlm1603_9

Michaelsen, L. K., \& Richards, B. (2005). Drawing conclusions from the team-based learning literature in health-sciences education. Teaching and Learning in Medicine, 17(1), 85-88. http://dx.doi.org/10.1207/s15328015tlm1701_15

Michaelsen, L. K. (1983). Team learning in large classes. New Directions for Teaching and Learning, 14, 13-22. http://dx.doi.org/10.1002/t1.37219831404

Michaelsen, L. K. (2008). Team-based learning for health professions education: A guide to using small groups for improving learning. Stylus Publishing: Sterling, VA.

Michaelsen, L. K., \& Sweet, M. (2008). The essential elements of team-based learning. New Directions for Teaching and Learning, 116, 7-27. http://dx.doi.org/10.1002/t1.330

Michaelsen, L. K., Knight, A. B., \& Fink L. D. (2002). Team-based learning: A transformative use of small groups. Greenwood Publishing Group: Santa Barbara, CA.

Miller, C. J., \& Metz, M. J. (2014). Birds of a feather flock together: The importance of seating location with active learning in the professional classroom. Adv Physiol Edu, 38, 181-182. http://dx.doi.org/10.1152/advan.00019.2014

Miller, C. J., Aiken, S., \& Metz, M. J. (2015). Perceptions of D.M.D. student readiness for basic science courses in the United States: Can online review modules help? Eur $J$ Dent Educ, 19, 1-7. http://dx.doi.org/10.1111/eje.12094

Miller, C. J., McNear, J., \& Metz, M. J. (2013). A comparison of traditional and engaging lecture methods in a large, professional-level course. Adv Physiol Edu, 37, 347-355. http://dx.doi.org/10.1152/advan.00050.2013

Neumann, M., Edelhäuser, F., Tauschel, D., Fischer, M. R., Wirtz, M., Woopen, C., Haramati, A., \& Scheffer, C. (2011). Empathy decline and its reasons: A systematic review of studies with medical students and residents. Academic Medicine, 86(8), 996-1009. http://dx.doi.org/10.1097/ACM.0b013e318221e615

Park, S. E., \& Howell, T. H. (2015). Implementation of a flipped classroom educational model in a predoctoral dental course. $J$ Dent Educ, 79(5), 563-570. 
Parmelee, D. X. (2010). Team-based learning: Moving forward in curriculum innovation: A commentary. Medical Teacher, 32, 105-107. http://dx.doi.org/10.3109/01421590903548554

Parmelee, D. X., Michaelsen, L. K., Cook, S., \& Hudes, P. D. (2012). Team-based learning: A practical guide: AMEE Guide No. 65. Medical Teacher, 34, 275-287. http://dx.doi.org/10.3109/0142159X.2012.651179

Prinz, P., Hertrich, K., Hirschfelder, U., \& de Zwaan, M. (2012). Burnout, depression and depersonalization-psychological factors and coping strategies in dental and medical students. GMS Z Med Ausbild, 29(1), 10-19.

Rolfe, I., \& McPherson, J. (1995). Formative assessment: how am I doing? The Lancet, 345(8953), 837-839. http://dx.doi.org/10.1016/S0140-6736(95)92968-1

Silverstein, S. T., \& Kritz-Silverstein, D. (2010). A longitudinal study of stress in first-year dental students. $J$ Dent Educ, 74(8), 836-848.

Sweet, M., \& Michaelsen, L. K. (2007). How group dynamics research can inform the theory and practice of postsecondary small group learning. Educ Psychol Rev, 19, 31-47. http://dx.doi.org/10.1007/s10648-006-9035-y

Takeuchi, H., Omoto, K., Okura, K.,Tajima, T., Suzuki, Y., Hosoki, M., Koori, M., Shigemoto, S., Ueda, M., Nishigawa, K., Rodis, O. M. M., \& Matsuka, Y. (2015). Effects of Team-Based Learning on Fixed Prosthodontic Education in a Japanese School of Dentistry. J Dent Educ, 79(4), 417-423.

Troth, A. C., Jordan, P. J., \& Lawrence, S. A. (2012). Emotional intelligence, communication competence, and student perceptions of team social cohesion. Journal of Psychoeducational Assessments, 30(4), 414-424. http://dx.doi.org/10.1177/0734282912449447

University of Louisville School of Dentistry. D.M.D. Program: USLD Student Body. Retrieved March 28, 2015, from http://louisville.edu/dentistry/degrees/dmd

University of Louisville School of Medicine. Student Profile: Entering Class of 2013. Retrieved March 28, 2015, from http://louisville.edu/medicine/admissions/student-profile

Vasan, N. S., DeFouw, D. O., \& Compton, S. (2009). A survey of student perceptions of team-based learning in anatomy curriculum: favorable views unrelated to grades. Anat Sci Educ, 2, 150-155. http://dx.doi.org/10.1002/ase.91 